\title{
Formation of Systematic Management Knowledge as an Important Component of Modern Political Education
}

\author{
Alexander Kulinchenko \\ Financial University under the Government of the Russian \\ Federation \\ Moscow, Russia \\ E-mail: AVKulinchenko@fa.ru
}

Elena Ageeva

Financial University under the Government of the Russian Federation

Moscow, Russia

E-mail: eaageeva@fa.ru

\author{
Yulia Mamaeva \\ Financial University under the Government of the Russian \\ Federation \\ Moscow, Russia \\ E-mail: YAMamaeva@fa.ru \\ Nikolay Sedykh \\ Financial University under the Government of the Russian \\ Federation \\ Moscow, Russia \\ E-mail: sedychnikolaj@yandex.ru
}

\begin{abstract}
The paper analyzes the approaches to solving tasks on managerial knowledge and skills formation. It justifies the necessity for students to acquire the systematic knowledge of social processes management as it meets the requirements of the emerging and developing information society. It summarizes the importance of preparing future politicians, political scientists and managers prepared for changes in the system of social management and for the widely used information technologies.
\end{abstract}

Keywords-political education; information society; society management system; systematic knowledge of management; development management

\section{INTRODUCTION}

The knowledge of social management is an integral part of political education and acquiring knowledge of politics and political life. The idea of politics as an art of governing a state, which goes back to Plato has not yet lost its significance in the 21 st century [1]. However, the object of management itself, the society in the totality of its constituent elements, the overall system of social relations and the organization of the society, has become much more complicated. The ongoing changes are inevitably reflected in the political sphere of public life. The diversity of policy actors, the complexity of relationship between them, their rivalry and competition for public power are expected to contribute to a strong and effective system of political institutions, among which the state is the central one. Politics should lead to the formation of the government institutions system and the strategy adopted by the society (state policy), which is effectively implemented by state administration in immediate interaction with all political forces and the civil society of the country.
Such complex and diverse tasks require politicians, public officials and political experts to possess profound knowledge and skills, which are largely formed by political education. It is critical to make deliberate efforts to ensure that people aimed at managing the affairs of the society are not guided by limited, fragmentary and therefore distorted ideas about the essence, content and mechanisms of such a serious activity. Consequently, it is all about the system of social management and the need to gain systematic knowledge on such a complex process.

\section{PRACTICE-ORIENTATION AS A FUNDAMENTAL TREND IN POLITICAL EDUCATION}

Objectively speaking, practice-orientation can be considered an underlying trend in modern political education in Russia.

With regard to management issues, this tendency is particularly manifested in design and rapid development of scientific and academic discipline "political management". This is entirely justified, as there exist in practical problems that need to be studied and solved; which will not be feasible if acting politicians are not equipped with the relevant knowledge. However, every phenomenon has a downside and political management is no exception: the focus here is mostly on means, mechanisms and technologies. The most common view on the essence of political management is to understand it as a type of management in politics, which resorts to special techniques and ways of solving its problems and uses a variety of political technologies [2]. Naturally, technological effectiveness, being based on solid theoretical and methodological grounds, is commonly seen as an advantage of a practice-oriented discipline. If technology starts to prevail over theory in educational 
process, there is a high risk of truly dangerous circumstances. Problem solving mechanisms sometimes are applied without their full understanding, which obviously results in various negative consequences. Knowledge (theories, concepts) and their practical use (technologies, ways) constitute a close unity, beyond which they are meaningless and even not applicable. As stated by Bulgakov S.N., "in reality, knowledge does not exist as something purely theoretical, if such, it is an abstraction, it exists only in a concrete unity of action, and so does its moment". In other words, a theory of knowledge-based action is sufficient [3]. Following the so-called "useful" technological knowledge not infrequently destroys this unity, underestimates or limits the role of theory and methodology, distorting the basic concepts.

The subject of political management is increasingly perceived by students as a kind of demiurge, which creates social and political reality and successfully achieves goals with the help of information technologies, PR, GR, political marketing, advertising, branding, image making and even by mass consciousness manipulation. It cannot be denied that such a result is rather possible in real life. The question is to what extent this is the process and result of management itself. Indeed, the concept of management does not equal the use of political technologies in order to achieve a goal. The latter is also a means of implementing politics, including political forces confrontation.

Initially, management was understood as a specially trained person's (manager's) activity, when they perform a special kind of activity, management work, on a professional basis and carry out management functions in the process of achieving the goals of an organization [4]. However, an organization operates in a social environment, so its goals can be achieved only if the manager is able to take into account and apply the knowledge of social, political, economic, psychological, cultural and other patterns, as they are objective factors and conditions for achieving goals. For political organizations, the task is even more challenging, as they often oppose each other. As a result, reaching particular goals of political organizations can lead to devastating consequences for the society as a whole. The Pyrrhic victory in the future will negatively affect the "winner", but such destructive effects of goals achievement are somewhat opposite to management.

Consequently, management is based on awareness of management laws. It is a sort of social management, when people solve specific tasks and perform management functions in well-defined, specific processes. It is also a part of a general management process, implementation of an essential function of the social system. The task of managing society as a whole is immeasurably more difficult, since it requires a large-scale targeted impact, which moves the social system to a new level, increasing the potential of its sustainable development. Managing society, one cannot do without the knowledge of fundamental social development laws and establishment of special institutions of public, state authority.

Summarizing the above-mentioned facts, we can conclude that with respect to gaining managerial knowledge two practice-oriented models of political education are being formed. The first of them involves training professional political consultants, assistants, specialists in the field of goals achievement and other political actors. The functions of these specialists are in high demand by political leaders, but their activities are limited by their patrons.

The second model is designed in order to satisfy the need in qualitatively different specialists: authors of political theories, concepts, strategies, ideologies capable of reasoning and explaining critical problems of developing society as a whole and proposing ways of solving these problems.

Accordingly, modern political education should be structured in such a way that professional training is carried out in line with the objectives of both of the models, as they are inseparably interconnected. Both theory and technology (theoretical and applied knowledge) as a close unity should be focused on solving practical tasks of social development and managing this development.

\section{THE TASKS OF POLITICAL EDUCATION AS A CONSEQUENCE OF UNDERSTANDING DEVELOPMENT PROCESSES IN MODERN SOCIETY}

Modern society is actively developing in various areas. Qualitative changes are taking place in the economy, technology, social and political sphere, culture, science and education. However, development of the information society is believed to be one of the most important trends that brings together the multidimensional process of social evolution. It is often described as the society where production and use of information grow in the avalanche-like way. Obviously, information has been used before, that is why the quantitative growth in information use itself cannot be considered an explicit characteristic of the changes happening. It is difficult to resist the conclusion by $\mathrm{F}$. Webster that the information society is fundamentally different from all previous societies. The essence of this difference is that the nature of information "has changed the way we live" [5].

However, many researchers are currently paying more attention to the technological side of the issue, primarily considering new information technologies a means of persuading people. A special term "information management" has even appeared to denote the management type applied mostly through mass media. According to $\mathrm{H}$. Tumber, information management is necessary to ensure the coordinated work of modern government. The state entirely relies on communication and information to manipulate public opinion and exercise social control [6]. New media jobs have appeared, as well as specially trained professionals in information technologies, propaganda, advertising and PR, who are engaged in providing the interaction between politicians, businessmen and the media in order to influence public opinion.

There is no doubt that this is a significant activity in terms of establishing mutual understanding within the society and improving public relations. Nevertheless, the problem of manipulating public opinion with its 
unpredictable consequences for the society remains underestimated. As F. Webster says, the fundamental principle is to disseminate the information in the interests of those who pay for it, i.e. to manage the information environment in order to control people's actions [7]. The authors of the World Bank report also highlight the danger of corporations and government structures taking advantage of modern digital technologies not for empowering citizens, but for total control over them [8].

Evidently, the members of modern society that is experiencing cardinal changes are not placing their hopes in these consequences. An important aspect of the changes taking place is forming not only information, but also a network society. The Internet connects the existing communication networks, creating new connections and structures, combining resources and providing new forms of social organization. According to $\mathrm{M}$. Castells, networkcreating power as the highest form of power in a network society. At the same time, in the world of networks the holders and source of power act as networks themselves: they are people who rally around their projects and interests and ensure interaction based on shared goals. In a network society, culture and its products (ideas, concepts, and projects) are most involved in communication processes [9].

In new conditions, power clearly reveals its major characteristic feature - the unifying and directing force drawn from people's communication. According to $\mathrm{N}$. Luhmann, power acts as a code-driven communication, a symbolically generalized communication tool. Communicative means are formed where the method of selection carried out by one of the partners serves a motivational structure to the other one. Communicative processes controlled by these means connect partners and direct them [10].

This, in turn, unveils the deep essence of social management as a special kind of interaction between people. It has always existed, ensured the working capacity of institutions, united and guided society development, but it did not get much attention because of more typical elements of social management — public administration and management. Nowadays, the function of social management in certain conditions can be a part of any activity, regardless of its content. To be more precise, management is the result of activity exchange (their products, results, accomplishments), which is obtained in the long view of human culture and creativity development. Management represents relevant information (informational influence) about solving new tasks and reaching higher levels of individual and social development. Management is the result of creative activity, which is able to provide joint activities for many people based on production of ideas, values, norms, algorithms and patterns of behavior that, when perceived by other participants in the activity exchange, contribute to satisfying their needs and achieving their goals [11].

The changes brought by information society development lead to theoretical knowledge playing a dominant role in such a type of society. This knowledge is not ad-hoc, but generalized and coded, with high potential in terms of influencing the future [12]. Finally, not only is management connected with power, communication and informational influence, but it also deals with future controlling development.

What is meant is the development of the society as a whole and of its numerous components up to the final subject of all social changes and accomplishments - an individual who applies the total heritage of human culture to solving a particular creative task. An individual is able to take up the role of the subject of management, to become a partner to public administration institutions when looking for the best solution to the problems that arise.

In addition, the state keeps acting as the central institution of public authority and society management as a whole. At the same time, in the exceptionally sophisticated system of modern society, there occur countless connections, which are impossible to control from a single center. This has never been possible and has never been the first-priority task. Nevertheless, the processes of self-organization, selfregulation, and self-government, generated by the creative activity of individuals, groups, and network structures, are much more developed nowadays. Therefore, the process of managing modern society is a system of organizing and regulating processes and interactions, which include both state administration and the spontaneous processes of selfgovernment listed above. One of the prominent conclusions of synergetics as a theory of self-organization is the proposition that for the sustainable development of complex social structures both proportions of spontaneity of development and self-management, and external management and control are equally important. Moreover, these two components, employees' self-organization and topdown management, should be balanced and coordinated with each other [13]. Three or four decades ago, the statement that state administration is "organizational cooperation between the state and groups, individuals in the society," interaction of the parties aimed at achieving common goals [14] could have been perceived as something abstract and purely theoretical. Today, management through cooperation represents the major direction of development of both theory and practice of public administration [15]

Political education should meet modern challenges in social development, should form a solid knowledge and skills base in social and political processes management. It presupposes not only a combination of deep theoretical training and mastery of modern management and political technologies. Today, there is a demand for analyzing ways of solving managerial tasks and understanding subjects and objects of management as a complex system, which should be directed towards goals of developing the society and all its components. In turn, this requires special training, scope of general knowledge and preserving cultural heritage. Without the components mentioned, it is impossible to organize public interaction and cooperation between the subjects of various activity types, including managerial and political activity, effectively. 


\section{SySTEMATIC KNOWLEDGE AS A BASIS FOR MANAGING THE SOCIETY}

The changes taking place in modern society lead to society management gradually but increasingly becoming the knowledge management or the management based on knowledge of fundamental trends and patterns of developing the society as a complex system. Therefore, political education should form a corresponding system of managerial knowledge and skills. There are a number of key elements of the knowledge system to emphasize in this respect.

Primarily, it is mastering general knowledge in the field of management theory. It is extremely desirable for political scientists to acknowledge the inextricable connection of their professional activities in solving managerial problems with understanding the management phenomenon itself. In its broad sense, management is defined as a function of organized systems of different nature, which ensures their specific structure, maintains the established activity mode and is aimed at achieving its goals [16]. Management deals with the process of working out and implementing managerial actions over the object of management in order to achieve goals of management [17], which implies developing the system and raising the level of its organization.

Secondly, an integral element of training is studying the theory of public administration, considering the state not only the central institution of political system, which implement public policy, but also the managing subsystem of the public system and the subject of public administration.

Thirdly, knowledge and skills in the field of general and political management are required, as they reveal the way the management function is performed. Combining theoretical knowledge and practical skills, mastering managerial, political and modern information technologies is essential. Management as administrating an organization to achieve certain, i.e. political goals (goals of political actors) generates a special task of acquiring knowledge and skills for managing conflicts, reaching compromise based on solidarity and cooperation. Otherwise, technology as a means is capable of displacing the ultimate goal of social management, which is sustainable development as a single whole in the unity of its parts, by prevalence of one part of the society over the other one, which can lead to a general society loss.

Fourth, there is a need to know and master the methodology for analyzing the way the modern information network society is organized. This type of social management with special intensity demonstrates its ability to set and achieve goals in the process of cooperation and engagement in various types of people's activity to solve creative tasks for the benefit of all the participants and the society in general.

Special attention should be paid to a challenging task in the political scientists preparation: the acquisition of in-depth knowledge of the relationship between politics and management at all levels of society organization, in solving public policy and society management problems, or in the process of setting and achieving goals of political management. Politics and management go hand in hand and complement each other. Proceeding from contradictions and conflicts of interests, politics unites them to form the national policy, based thereon. Then it comes to state management as practical implementation of fundamental goals of state policy. However, in the management process new circumstances and disagreements may arise reviving political opposition. This is how politics turns management and management turns politics, and it is the direct task of politicians and political scientists to recognize and take into account this complex interrelation.

Another important task, solving which is made difficult in modern conditions, is multidisciplinary training for specialists that will provide theoretical and methodological basis for analytical and practical activities and its general cultural grounds. Niche specialization knowledge and skills should not totally dominate broad and profound knowledge in numerous areas: history, philosophy, law, economics, sociology, psychology, culture studies, etc. For the sake of maximizing time, obtaining bread knowledge is frequently neglected due to reducing curricula and providing more opportunities for self-study. Some students take advantage of the given freedom, but the large proportion following the same "rational" approach opt for not wasting their time and effort on something the educational system itself considers optional.

With regard to management, it can be definitely said that what is got as a result is not at all the rational Weber's bureaucracy based on professional knowledge, but bureaucracy as formalism, red tape and inefficiency in achieving management goals. For a particular manager, this means, that the instructions of their boss get overall significance. They completely rely on their boss in general issues, as the boss relies on the subordinates in solving specific issues. As noted by $\mathrm{K}$. Marx, this is the way they "mislead each other".

Management and politics are such important areas of human activity that we cannot be guided by illusions. Modern society requires a different way - resorting to management based on knowledge, in fact, the integrated system of knowledge, capable of solving crucial problems and thus, improving the life of the society for the better.

\section{CONCLUSION}

Managing the society and socio-political processes, which constitute a system, can be carried out only through a relevant complex management system. This is what people who perform management functions on a professional basis, politicians, managers, and political scientists should be prepared for. Education as a public institution is designed to provide the required level of political training for the people involved. Political education in the field of managerial knowledge should provide an integrated system of training that is able to build system-wide knowledge and skills in politics and management to meet the demands of the society. Fragmentary, superficial, outdated knowledge and approaches not only will prevent people from fulfilling their professional duties effectively, but taking into account the 
role of management and politics in the society, they may also cause significant damage or undermine the process of achieving goals. The systematic knowledge of management guarantees that trained professionals operating in management will be able to cope with the increasing flow of information in modern world, will transform useful information into key decisions that control the development of the society.

\section{REFERENCES}

[1] Plato. Collected edition, in 4 volumes. Moscow, 1994. V. 4, pp. 62-63.

[2] Pushkareva G.V. Political management. Moscow. 2002. P. 21.

[3] Bulgakov S.N. The philosophy of the economy. In 2 volumes. Moscow. 1993. V. 1, pp. 193-197.

[4] Meskon M., Albert M., Khedouri F. Fundamentals of Management: Trans. from English. Moscow. 1992, pp. 27-60.

[5] Webster F. Theories of the Information Society. Moscow. 2004. P. 14.

[6] Tumber H. Taming the Truth. British Journalism Review, 4 (1). 1993. P 37.

[7] Webster F. Theories of the Information Society. Moscow. 2004, pp. 259-260.

[8] World Bank. World Development Report 2016 "Digital Dividends". Overview. World Bank, Washington, DC. License: Creative Commons Attribution CC BY 3.0 IGO. [Electronic resource] URL: https://openknowledge.worldbank.org/bitstream/handle/10986/23347/ 210671RuSum.pdf (access date: 09/28/2018).

[9] Castells M. The power of communication. Moscow. 2016, pp. 63-65.

[10] Luhmann N. Power. Moscow. 2001. P. 16-33.

[11] Kulinchenko A.V. Leadership and social management. The essence and importance of social management. // "Humanitarian sciences. Bulletin of the Financial University, №3. Moscow. 2015, pp. 38-45.

[12] Webster F. Theories of the Information Society. Moscow. 2004, pp. 37-38, 371.

[13] Kurdyumov S.P., Knyazeva E.N. Coevolution of complex social structures: the balance of self-organization and management // Strategies of the dynamic development of Russia: the unity of selforganization and management. Moscow, 2004. V. 1. P. 123, 145.

[14] Kurashvili B.P. Essays on the theory of state administration. Moscow. 1987, pp. 88-89.

[15] Public Policy Management: Collective Monograph. Moscow. 2015.

[16] Philosophical Encyclopedia. Moscow. 1970. V. 5. P. 282.

[17] Management Theory. Terminology. Issue 107. Moscow. 1988. 